\title{
Plant Extracts Affect In Vitro Rumen Microbial Fermentation
}

\author{
M. Busquet, ${ }^{*}$ S. Calsamiglia, ${ }^{* 1}$ A. Ferret, ${ }^{*}$ and C. Kamel† \\ *Departament de Ciència Animal i dels Aliments, Universitat Autònoma de Barcelona, 08193 Bellaterra, Spain \\ †Pancosma S.A., 01205 Bellegarde-sur-Valserine Cedex, France
}

\section{ABSTRACT}

Different doses of 12 plant extracts and 6 secondary plant metabolites were incubated for $24 \mathrm{~h}$ in diluted ruminal fluid with a 50:50 forage:concentrate diet. Treatments were: control (no additive), plant extracts (anise oil, cade oil, capsicum oil, cinnamon oil, clove bud oil, dill oil, fenugreek, garlic oil, ginger oil, oregano oil, tea tree oil, and yucca), and secondary plant metabolites (anethol, benzyl salicylate, carvacrol, carvone, cinnamaldehyde, and eugenol). Each treatment was supplied at $3,30,300$, and $3,000 \mathrm{mg} / \mathrm{L}$ of culture fluid. At $3,000 \mathrm{mg} / \mathrm{L}$, most treatments decreased total volatile fatty acid concentration, but cade oil, capsicum oil, dill oil, fenugreek, ginger oil, and yucca had no effect. Different doses of anethol, anise oil, carvone, and tea tree oil decreased the proportion of acetate and propionate, which suggests that these compounds may not be nutritionally beneficial to dairy cattle. Garlic oil (300 and $3,000 \mathrm{mg} / \mathrm{L}$ ) and benzyl salicylate (300 and $3,000 \mathrm{mg} / \mathrm{L}$ ) reduced acetate and increased propionate and butyrate proportions, suggesting that methane production was inhibited. At $3,000 \mathrm{mg} / \mathrm{L}$, capsicum oil, carvacrol, carvone, cinnamaldehyde, cinnamon oil, clove bud oil, eugenol, fenugreek, and oregano oil resulted in a 30 to $50 \%$ reduction in ammonia $\mathrm{N}$ concentration. Careful selection and combination of these extracts may allow the manipulation of rumen microbial fermentation.

Key words: plant extract, rumen fermentation

\section{INTRODUCTION}

Ruminal fermentation of hexoses and amino acids is accompanied by losses of energy and amino N, respectively. In fact, 8 to $12 \%$ of the digestible energy ingested by ruminants is lost in the rumen as methane, whereas from 75 to $85 \%$ of the $\mathrm{N}$ consumed by dairy cows is excreted in feces and urine (Tamminga, 1992). Modification of rumen microbial fermentation to decrease methane and ammonia $\mathrm{N}$ production using feed

Received October 14, 2004.

Accepted September 23, 2005.

${ }^{1}$ Corresponding author: sergio.calsamiglia@uab.es additives, such as antibiotics, has proved to be a useful strategy to improve production efficiency in dairy cattle (McGuffey et al., 2001). However, the use of antibiotics as feed additives in dairy cows is banned in the European Union due to the potential of appearance of residues in milk (Russell and Houlihan, 2003). For this reason, there is substantial interest in evaluating the potential of natural antimicrobials such as plant extracts, generally recognized as safe for human consumption (FDA, 2004), to modify rumen microbial fermentation.

Plant extracts have been used for centuries for various purposes (as traditional medicine and food preservatives, among others) due to their antimicrobial properties (Davidson and Naidu, 2000). The antimicrobial activity of plant extracts is attributed to a number of secondary plant metabolites, which include saponins (present in extracts of Yucca schidigera or Trigonella foenum graecum), terpenoids (such as carvacrol, carvone, thymol, or terpinen-4-ol) and phenylpropanoids (like cinnamaldehyde, eugenol, or anethol) present in the essential oil fraction of many plants. Limited data are available on the effect of plant extracts on rumen microbial fermentation. Previous in vitro continuous culture studies conducted in our laboratory (Cardozo et al., 2004; Busquet et al., 2005b) with doses from 0.22 to $2.2 \mathrm{mg} / \mathrm{L}$ of culture fluid of different plant extracts and secondary plant metabolites demonstrated the potential of some extracts to modify rumen microbial fermentation, but the authors suggested that the doses used may have not been adequate. The in vitro batch culture short-term incubation system was chosen as a rapid and inexpensive method to screen the main effects of different compounds at different doses simultaneously.

The objective of the present study was to screen effects of different doses of 12 plant extracts and 6 secondary plant metabolites on total and individual VFA, ammonia $\mathrm{N}$ concentration, and $\mathrm{pH}$ in a rumen microbial batch fermentation system.

\section{MATERIALS AND METHODS}

\section{In Vitro Batch Fermentations}

The effects of various plant extracts on rumen microbial fermentation were evaluated in in vitro batch cul- 
ture of rumen fluid supplied with a 50:50 forage:concentrate diet $(17.3 \% \mathrm{CP}, 28.0 \% \mathrm{NDF}$, and $17.7 \% \mathrm{ADF}$, DM basis). The diet (DM basis) consisted of alfalfa hay $(49.4 \%)$, ground barley grain $(24.0 \%)$, ground corn grain $(15.4 \%)$, soybean meal $(9.7 \%)$, monobasic sodium phosphate $\left(\mathrm{H}_{2} \mathrm{NaPO}_{4} \cdot 2 \mathrm{H}_{2} \mathrm{O}, 0.4 \%\right)$, white salt $(\mathrm{NaCl}$, $0.3 \%$ ), and a vitamin and mineral mixture $[0.4 \%$; containing (mg/kg): $7 \mathrm{Co}, 167 \mathrm{Cu}, 33 \mathrm{I}, 2,660 \mathrm{Mn}, 27 \mathrm{Se}$, and $4,660 \mathrm{Zn} ; 1,000 \mathrm{kIU}$ of vitamin A, $200 \mathrm{kIU}$ of vitamin $\mathrm{D}_{3}$, and $1,330 \mathrm{mg}$ of vitamin $\mathrm{E} ; 2.67 \mathrm{~g}$ of urea, $67 \mathrm{~g}$ of $\mathrm{NaCl}, 33 \mathrm{~g}$ of $\mathrm{S}$, and $300 \mathrm{~g}$ of $\mathrm{MgO}$. The diet was designed to meet or exceed nutrient recommendations for a Holstein cow $(650 \mathrm{~kg})$ producing $30 \mathrm{~kg}$ of milk (NRC, 2001). Treatments were: control (no additive), anise oil (Pimpinella anisum, standardized at $86 \%$ of anethol), cade oil (Juniperus oxycedrus, standardized at $35 \% \alpha$-pinene), capsicum oil (Capsicum annuum, standardized at $12 \%$ of capsaicin), cinnamon oil (Cinnamonum cassia, standardized at $59 \%$ of cinnamaldehyde), clove bud oil (Syzygium aromaticum, standardized at $85 \%$ of eugenol), dill oil (Anethum graveolens, standardized at $47 \%$ of carvone), extract of fenugreek (Trigonella foenum graecum, standardized at $18 \%$ of sarsaponins), garlic oil (Allium sativa, standardized at $0.7 \%$ of allicin), ginger oil (Zingiber officinale, standardized at $18 \%$ of shagaols), oregano oil (Origanum vulgare, standardized at $69 \%$ of carvacrol), tea tree oil (Melaleuca alternifolia, standardized at $42 \%$ of 1-terpinen-4-ol), extract of yucca (Yucca schidigera, standardized at $8 \%$ of sarsaponin), and the secondary metabolites: anethol $\left(\mathrm{C}_{10} \mathrm{H}_{12} \mathrm{O}\right.$, purity of $99 \%)$, benzyl salicylate $\left(\mathrm{C}_{14} \mathrm{H}_{12} \mathrm{O}_{3}\right.$, purity of $\left.99 \%\right)$, carvacrol $\left(\mathrm{C}_{10} \mathrm{H}_{15} \mathrm{O}\right.$, purity of $\left.>99 \%\right)$, carvone $\left(\mathrm{C}_{10} \mathrm{H}_{14} \mathrm{O}\right.$, purity of $99 \%)$, cinnamaldehyde $\left(\mathrm{C}_{9} \mathrm{H}_{8} \mathrm{O}\right.$, purity of $98 \%$ ), and eugenol $\left(\mathrm{C}_{10} \mathrm{H}_{12} \mathrm{O}_{2}\right.$, purity of $\left.98 \%\right)$. Plant extracts and secondary metabolites were provided by Pancosma S. A. (Bellegarde-sur-Valserine Cedex, France). Four different doses were used for each compound: $3,30,300$, and $3,000 \mathrm{mg} / \mathrm{L}$ of the total culture fluid. Compounds were tested in triplicate at each dose, and fermentations were repeated on 2 separate days. Ruminal fluid was obtained from 2 rumen-fistulated dairy cows fed a 50:50 forage:concentrate diet. The diet (DM basis) consisted of alfalfa hay (34.9\%), ryegrass hay $(14.8 \%)$, ground barley grain $(11.4 \%)$, ground corn grain $(11.4 \%)$, soybean meal $(1.6 \%)$, cottonseed $(7.9 \%)$, corn gluten feed $(11.6 \%)$, molasses $(3.2 \%)$, calcium soaps of fatty acids $(1.3 \%)$, and a mineral and vitamin mix $(2.1 \%)$. The diet was designed to meet or exceed nutrient recommendations for a Holstein cow $(650 \mathrm{~kg})$ producing $30 \mathrm{~kg}$ of milk (NRC, 2001). Fluid was strained through 4 layers of cheesecloth, mixed in a 1 to 1 proportion with phosphate-bicarbonate buffer (McDougall, 1948), purged with anaerobic grade $\mathrm{CO}_{2}\left(<2 \mathrm{ppm} \mathrm{O}_{2}\right)$, and standardized at $\mathrm{pH} 7.0$ \pm 0.1 with $3 \mathrm{~N} \mathrm{HCl}$. The fermentation process was conducted in $90-\mathrm{mL}$ polypropylene tubes containing $50 \mathrm{~mL}$ of culture fluid with $0.5 \mathrm{~g}$ of the diet ground through a 1-mm screen. The lipid-soluble additives (oils and secondary plant metabolites) were dissolved in ethanol in different proportions, and a total of 0.15 $\mathrm{mL}$ was added to the culture fluid. Fenugreek and yucca were dissolved in water, and a total of $0.15 \mathrm{~mL}$ was added to the culture fluid. The equivalent amount of ethanol $(0.15 \mathrm{~mL})$ was added to control, fenugreek, and yucca tubes. Tubes were purged with anaerobic grade $\mathrm{CO}_{2}\left(<2 \mathrm{ppm} \mathrm{O}_{2}\right)$ before sealing with rubber stoppers. Incubations were conducted at $39^{\circ} \mathrm{C}$ in a shaking waterbath. After $24 \mathrm{~h}$, the $\mathrm{pH}$ was determined in culture fluid and samples for ammonia $\mathrm{N}$ and VFA were collected for analyses.

\section{Chemical Analyses}

The $\mathrm{pH}$ was determined in culture fluid at the end of the 24-h fermentations with a $\mathrm{pH}$ meter (model 5200, Crison, Alella, Barcelona, Spain).

Samples for VFA were prepared following the method described by Jouany (1982) with modifications. In brief, $1 \mathrm{~mL}$ of a solution made up of a $0.2 \%$ (wt/ wt) solution of mercuric chloride, $0.2 \%(\mathrm{wt} / \mathrm{wt})$ of 4 methylvaleric acid as an internal standard, and $2 \%$ (vol/vol) orthophosphoric acid, was added to $4 \mathrm{~mL}$ of filtered rumen fluid and frozen. Samples were centrifuged at $3,000 \times g$ for $30 \mathrm{~min}$, and the supernatant was analyzed by gas chromatography (model 6890, Hewlett Packard, Palo Alto, CA) using a polyethylene glycol nitroterephthalic acid-treated capillary column (BP21, SGE, Europe Ltd., Buckinghamshire, UK).

For ammonia $\mathrm{N}$ determinations, a 4-mL sample of filtered fermenter fluid was acidified with $4 \mathrm{~mL}$ of 0.2 $N \mathrm{HCl}$, and frozen. Samples were centrifuged at 25,000 $\times g$ for $20 \mathrm{~min}$, and the supernatant was analyzed by visible spectrophotometry for ammonia N (Chaney and Marbach, 1962).

\section{Statistical Analyses}

The effects of different doses of each compound compared with control were tested using the PROC MIXED procedure of SAS (version 8.12; SAS Institute, Cary, NC) with day treated as a random effect, according to the model: $y_{i}=D_{i}+e_{i}$, where $y_{i}$ was the dependent variable, $D_{i}$ was the dose effect, and $e_{i}$ the error term. When the overall $F$-test was significant, differences between means and the control were declared significant at $P<0.05$ using the Dunnett comparison test; treatment results are reported as least squares means. 
Table 1. Effect of plant extracts on $\mathrm{pH}$ compared with control in in vitro rumen microbial fermentation of a 50:50 forage:concentrate diet

\begin{tabular}{llllllll}
\hline & \multicolumn{7}{c}{ Dose $(\mathrm{mg} / \mathrm{L})$} \\
\cline { 2 - 6 } Treatment & 0 & 3 & 30 & 300 & 3,000 & SEM $^{1}$ & $P<$ \\
\hline Anethol & 5.7 & 5.8 & 5.8 & $5.9^{*}$ & $6.1^{*}$ & 0.04 & 0.01 \\
Anise oil & 5.9 & 5.9 & 5.9 & 5.9 & $6.0^{*}$ & 0.08 & 0.07 \\
Benzyl salicylate & 5.7 & 5.8 & 5.8 & $5.8 \dagger$ & $5.8^{*}$ & 0.06 & 0.03 \\
Cade oil & 6.1 & 6.0 & 6.0 & 6.0 & $6.4^{*}$ & 0.09 & 0.03 \\
Capsicum & 5.9 & 6.0 & 5.9 & 5.9 & 5.9 & 0.37 & 0.43 \\
Carvacrol & 5.9 & 5.9 & 5.9 & $6.3^{*}$ & $7.2^{*}$ & 0.14 & 0.01 \\
Carvone & 5.7 & 5.8 & 5.8 & 5.8 & $6.4^{*}$ & 0.09 & 0.01 \\
Cinnamaldehyde & 5.9 & 5.9 & 5.9 & 6.0 & $6.9^{*}$ & 0.12 & 0.01 \\
Cinnamon oil & 5.7 & 5.8 & 5.8 & 5.8 & $6.1 \dagger$ & 0.10 & 0.13 \\
Clove bud oil & 5.7 & 5.8 & 5.8 & 5.9 & $7.0^{*}$ & 0.11 & 0.01 \\
Dillweed oil & 6.1 & 6.0 & 6.0 & 6.0 & $6.4^{*}$ & 0.11 & 0.01 \\
Eugenol & 5.9 & 5.9 & 5.9 & 6.0 & $7.1^{*}$ & 0.13 & 0.01 \\
Fenugreek & 6.1 & 6.1 & 6.1 & 5.9 & $5.7^{*}$ & 0.09 & 0.01 \\
Garlic oil & 5.9 & 5.8 & 6.0 & $6.0^{*}$ & $6.1^{*}$ & 0.04 & 0.01 \\
Ginger oil & 6.1 & 6.0 & 6.0 & 6.1 & $6.2^{*}$ & 0.08 & 0.03 \\
Oregano oil & 5.7 & 5.8 & 5.8 & 5.8 & $6.5^{*}$ & 0.13 & 0.01 \\
Tea tree oil & 5.9 & 5.9 & 5.9 & 5.9 & $6.3^{*}$ & 0.13 & 0.01 \\
Yucca & 5.9 & $5.8^{*}$ & $5.8^{*}$ & $5.8^{*}$ & $5.8^{*}$ & 0.34 & 0.01 \\
\hline
\end{tabular}

${ }^{1} \mathrm{SEM}=$ Standard error of the means.

*Means within a row differ significantly from control $(P<0.05)$.

$\dagger$ Means within a row differ from control $(P<0.08)$.

\section{RESULTS}

Relative to control, addition of high levels $(3,000 \mathrm{mg} /$ L) of all compounds resulted in an increase $(P<0.05)$ in $\mathrm{pH}$, except in capsicum and cinnamon oil (no change) and fenugreek and yucca extracts (decrease in $\mathrm{pH}, P$ $<0.05$; Table 1 ), and a reduction in the concentration of total VFA in all extracts except in cade, capsicum, dillweed, and ginger oils, and yucca and fenugreek extracts (Table 2). Anethol, carvacrol, clove bud oil, and oregano oil at $300 \mathrm{mg} / \mathrm{L}$ reduced the concentration of total VFA by $8.1,16.8,6.4$, and $4.3 \%$, respectively, compared with control.

The proportion of acetate (Table 3$)$ decreased $(P<$ 0.05 ) in anethol (at 30,300 , and $3,000 \mathrm{mg} / \mathrm{L}$ ); in anise oil, benzyl salicylate, and garlic oil (at 300 and 3,000 $\mathrm{mg} / \mathrm{L}$ ); in carvacrol and clove bud oil (at $300 \mathrm{mg} / \mathrm{L}$ ); and in carvone and tea tree oil (at $3,000 \mathrm{mg} / \mathrm{L}$ ). The proportion of acetate increased $(P<0.05)$ in cinnamon oil (at 3,000 mg/L). Cade oil, capsicum oil, cinnamaldehyde, dillweed oil, eugenol, fenugreek, ginger oil, oregano oil, and yucca extract had no effect on the proportion of acetate compared with control.

The proportion of propionate (Table 4$)$ increased $(P$ $<0.05$ ) in benzyl salicylate (at 300 and $3,000 \mathrm{mg} / \mathrm{L}$ ); in carvacrol, cinnamaldehyde, eugenol, fenugreek, and oregano oil (at $3,000 \mathrm{mg} / \mathrm{L}$ ); and in garlic oil (at 30 and $300 \mathrm{mg} / \mathrm{L}$ ). In contrast, at $3,000 \mathrm{mg} / \mathrm{L}$, the molar proportion of propionate decreased in anethol, anise oil, carvone, dillweed oil, and tea tree oil. Cade oil, capsicum oil, cinnamon oil, clove bud oil, ginger oil, and yucca extract had no effect on the proportion of propionate compared with control.

The proportion of butyrate (Table 5$)$ increased $(P<$ 0.05 ) in anethol, anise oil, and benzyl salicylate (at 300 and 3,000 mg/L); in carvacrol, clove bud oil, eugenol, and oregano oil (at $300 \mathrm{mg} / \mathrm{L}$ ); and in cade oil, carvone, dillweed oil, garlic oil, and tea tree oil (at $3,000 \mathrm{mg} / \mathrm{L})$. In contrast, the molar proportion of butyrate decreased $(P<0.05)$ in carvacrol and eugenol at $3,000 \mathrm{mg} / \mathrm{L}$. Capsicum oil, cinnamaldehyde, cinnamon oil, fenugreek, ginger oil, and yucca extract had no effect on the proportion of butyrate compared with control.

The proportion of branched-chain VFA (BCVFA; includes isobutyrate and isovalerate; Table 6) decreased $(P<0.05)$ in carvacrol, carvone, cinnamon oil, clove bud oil, fenugreek, and oregano oil (at $3,000 \mathrm{mg} / \mathrm{L}$ ); and in cinnamaldehyde and eugenol (at 300 and 3,000 $\mathrm{mg} / \mathrm{L})$. In contrast, it increased $(P<0.05)$ in tea tree oil. Anethol, anise oil, benzyl salicylate, cade oil, capsicum oil, dill oil, garlic oil, ginger oil, and yucca extract did not affect the proportion of BCVFA compared with control.

The concentration of ammonia (Table 7) decreased $(P<0.05)$ in capsicum oil, carvacrol, carvone, cinnamon oil, clove bud oil, eugenol, and oregano oil (at $3,000 \mathrm{mg} / \mathrm{L}$ ); and in cinnamaldehyde and fenugreek (at 300 and $3,000 \mathrm{mg} / \mathrm{L}$ ). In contrast, it increased in ginger oil and oregano oil at $300 \mathrm{mg} / \mathrm{L}$. The rest of the compounds did not modify the ammonia $\mathrm{N}$ concentration. 
Table 2. Effect of plant extracts on total VFA concentration $(\mathrm{m} M)$ compared with control in in vitro rumen microbial fermentation of a 50:50 forage:concentrate diet

\begin{tabular}{llllllrr}
\hline & \multicolumn{7}{c}{ Dose $(\mathrm{mg} / \mathrm{L})$} \\
\cline { 2 - 5 } Treatment & 0 & 3 & 30 & 300 & 3,000 & SEM $^{1}$ & $P<$ \\
\hline Anethol & 204.4 & 196.1 & 194.9 & $188.0^{*}$ & $171.0^{*}$ & 7.48 & 0.01 \\
Anise oil & 160.5 & 157.3 & 158.0 & 155.3 & $143.3^{*}$ & 5.34 & 0.04 \\
Benzyl salicylate & 204.4 & 201.7 & 198.1 & $196.1 \dagger$ & $191.3^{*}$ & 6.36 & 0.03 \\
Cade oil & 175.4 & 189.4 & 187.5 & 184.9 & 164.8 & 14.35 & 0.16 \\
Capsicum oil & 132.1 & 134.8 & 131.9 & 134.7 & 135.0 & 25.08 & 0.88 \\
Carvacrol & 187.3 & 182.8 & 183.7 & $155.9^{*}$ & $104.7^{*}$ & 5.97 & 0.01 \\
Carvone & 204.4 & 200.3 & 194.2 & 194.9 & $151.0^{*}$ & 6.22 & 0.01 \\
Cinnamaldehyde & 187.3 & 185.7 & 181.3 & 173.8 & $108.1^{*}$ & 4.87 & 0.01 \\
Cinnamon oil & 155.9 & 159.3 & 155.6 & 152.7 & $120.2^{*}$ & 12.38 & 0.01 \\
Clove bud oil & 204.4 & 199.2 & 198.3 & $187.1^{*}$ & $116.2^{*}$ & 8.60 & 0.01 \\
Dillweed oil & 175.4 & 187.6 & 186.5 & 188.8 & 168.9 & 15.99 & 0.34 \\
Eugenol & 187.3 & 182.7 & 186.0 & 175.5 & $107.4^{*}$ & 4.93 & 0.01 \\
Fenugreek & 175.4 & 184.5 & 183.4 & 186.7 & 192.7 & 12.12 & 0.33 \\
Garlic oil & 160.5 & 153.9 & 162.0 & 146.5 & $137.5^{*}$ & 5.93 & 0.06 \\
Ginger oil & 175.4 & 185.8 & 183.6 & 182.9 & 174.3 & 16.32 & 0.69 \\
Oregano oil & 155.9 & 154.2 & 153.2 & $149.6^{*}$ & $107.0^{*}$ & 12.73 & 0.01 \\
Tea tree oil & 187.3 & 181.3 & 182.6 & 178.7 & $156.8^{*}$ & 6.42 & 0.01 \\
Yucca & 132.1 & 129.8 & 134.0 & 131.4 & 133.6 & 24.31 & 0.87 \\
\hline
\end{tabular}

${ }^{1} \mathrm{SEM}=$ Standard error of the means.

* Means within a row differ significantly from control $(P<0.05)$.

$\dagger$ Means within a row differ from control $(P<0.08)$.

\section{DISCUSSION}

In general, rumen microbial activity was affected by the use of plant extracts and secondary plant metabolites. It is interesting to point out that when supplied at high levels $(3,000 \mathrm{mg} / \mathrm{L})$ most essential oils and their secondary constituents reduced the total VFA concentration compared with control, which is consistent with their antimicrobial activity (Davidson and Naidu, 2000). Volatile fatty acids are the end products of rumen microbial fermentation and represent the main supply of metabolizable energy for ruminants (Van Soest, 1982). Therefore, a reduction in their production would be nutritionally unfavorable for the ani-

Table 3. Effect of plant extracts on acetate molar proportion compared with control in in vitro rumen microbial fermentation of a 50:50 forage:concentrate diet

\begin{tabular}{llllllll}
\hline & \multicolumn{7}{c}{ Dose $(\mathrm{mg} / \mathrm{L})$} \\
\cline { 2 - 5 } Treatment & 0 & 3 & 30 & 300 & 3,000 & SEM $^{1}$ & $P<$ \\
\hline Anethol & 57.7 & 57.2 & $56.9^{*}$ & $56.0^{*}$ & $55.4^{*}$ & 0.89 & 0.01 \\
Anise oil & 51.5 & 51.5 & 51.3 & $51.0^{*}$ & $49.5^{*}$ & 0.08 & 0.01 \\
Benzyl salicylate & 57.7 & 58.1 & 57.8 & $57.0^{*}$ & $57.0^{*}$ & 0.64 & 0.01 \\
Cade oil & 57.3 & 58.7 & 58.7 & 57.7 & 55.3 & 1.56 & 0.14 \\
Capsicum oil & 52.6 & 53.1 & 52.6 & 52.7 & 52.6 & 2.49 & 0.76 \\
Carvacrol & 57.9 & 57.8 & 58.0 & $55.7^{*}$ & 57.6 & 2.02 & 0.01 \\
Carvone & 57.7 & 57.5 & 57.4 & $56.4 \dagger$ & $50.7^{*}$ & 0.72 & 0.01 \\
Cinnamaldehyde & 57.9 & 58.3 & 58.3 & 57.6 & 57.6 & 1.82 & 0.35 \\
Cinnamon oil & 51.5 & 51.9 & 51.6 & 51.6 & $54.3^{*}$ & 2.37 & 0.04 \\
Clove bud oil & 57.7 & 57.5 & 57.3 & $56.4^{*}$ & 57.0 & 0.98 & 0.07 \\
Dillweed oil & 57.3 & 58.8 & 58.5 & 58.0 & 55.6 & 1.65 & 0.16 \\
Eugenol & 57.9 & 57.9 & 57.8 & 57.6 & 57.4 & 1.96 & 0.64 \\
Fenugreek & 57.3 & 58.4 & 58.5 & 57.3 & 55.7 & 1.75 & 0.14 \\
Garlic oil & 51.5 & 51.1 & 50.7 & $46.2^{*}$ & $47.0^{*}$ & 0.33 & 0.01 \\
Ginger oil & 57.3 & 58.2 & 58.3 & 57.6 & 56.5 & 1.46 & 0.60 \\
Oregano oil & 51.5 & 51.5 & 51.5 & 50.6 & 52.1 & 2.33 & 0.11 \\
Tea tree oil & 57.9 & 57.8 & 57.8 & 57.3 & $54.9 *$ & 1.98 & 0.01 \\
Yucca & 52.6 & 52.8 & 53.2 & 52.6 & 51.4 & 2.42 & 0.12 \\
\hline
\end{tabular}

${ }^{1} \mathrm{SEM}=$ Standard error of the means.

*Means within a row differ significantly from control $(P<0.05)$.

$\dagger$ Means within a row differ from control $(P<0.08)$. 
Table 4. Effect of plant extracts on the propionate molar proportion compared with control in in vitro rumen microbial fermentation of a 50:50 forage:concentrate diet

\begin{tabular}{llllllll}
\hline & \multicolumn{7}{c}{ Dose $(\mathrm{mg} / \mathrm{L})$} \\
\cline { 2 - 6 } Treatment & 0 & 3 & 30 & 300 & 3,000 & SEM $^{1}$ & $P<$ \\
\hline Anethol & 27.3 & 27.4 & 27.7 & 27.6 & $25.1^{*}$ & 0.13 & 0.01 \\
Anise oil & 29.9 & 29.9 & 29.9 & 29.5 & $27.6^{*}$ & 0.42 & 0.01 \\
Benzyl salicylate & 27.3 & 27.0 & 27.3 & $27.8^{*}$ & $27.8^{*}$ & 0.10 & 0.01 \\
Cade oil & 26.9 & 26.1 & 26.2 & 26.9 & 27.6 & 1.63 & 0.22 \\
Capsicum oil & 30.8 & 30.8 & 30.9 & 30.9 & 31.0 & 1.63 & 0.91 \\
Carvacrol & 27.0 & 27.1 & 27.0 & $25.3^{*}$ & $29.9^{*}$ & 1.93 & 0.01 \\
Carvone & 27.3 & 27.3 & 27.4 & 27.3 & $20.5^{*}$ & 0.19 & 0.01 \\
Cinnamaldehyde & 27.0 & 26.9 & 26.9 & 27.1 & $29.5^{*}$ & 1.66 & 0.01 \\
Cinnamon oil & 31.2 & 31.1 & 31.1 & 31.1 & 31.2 & 0.80 & 0.99 \\
Clove bud oil & 27.3 & 27.3 & 27.5 & 27.0 & 28.2 & 0.31 & 0.18 \\
Dillweed oil & 26.9 & 26.1 & 26.2 & 26.4 & $22.1^{*}$ & 1.84 & 0.04 \\
Eugenol & 27.0 & 27.0 & 27.2 & 26.6 & $29.5^{*}$ & 1.86 & 0.01 \\
Fenugreek & 26.9 & 26.5 & 26.2 & 27.4 & $29.1^{*}$ & 1.70 & 0.01 \\
Garlic oil & 29.9 & 29.9 & $30.9 \dagger$ & $33.7^{*}$ & 31.1 & 0.31 & 0.01 \\
Ginger oil & 26.9 & 26.4 & 26.3 & 26.6 & 27.3 & 1.51 & 0.64 \\
Oregano oil & 31.2 & 31.5 & 31.4 & 30.4 & $33.1^{*}$ & 0.98 & 0.01 \\
Tea tree oil & 27.0 & 27.2 & 26.9 & 27.3 & $24.9^{*}$ & 1.96 & 0.01 \\
Yucca & 30.8 & 31.0 & 30.8 & 30.8 & 31.9 & 1.48 & 0.10 \\
\hline
\end{tabular}

${ }^{1} \mathrm{SEM}=$ Standard error of the means.

*Means within a row differ significantly from control $(P<0.05)$.

$\dagger$ Means within a row differ from control $(P<0.08)$.

mal. The observed increase in $\mathrm{pH}$ at $3,000 \mathrm{mg} / \mathrm{L}$ in most oils is also consistent with these results and reflects the lower concentration of VFA in the culture fluid. These results agree with the observations of $\mathrm{Oh}$ et al. (1967), who reported that high doses of different plant essential oils, tested on in vitro fermentation of mixed ruminal microorganisms, resulted in a general inhibition of rumen microbial fermentation.
Carvacrol is a phenolic monoterpenoid normally found in high quantities in oregano oil (containing $69 \%$ of carvacrol). In the present trial, oregano oil and carvacrol resulted in similar effects on $\mathrm{pH}$, total and individual VFA, and ammonia $\mathrm{N}$ concentrations, although carvacrol was more inhibitory compared with oregano oil. These results suggest that carvacrol is the main active compound in oregano oil, and agree with previ-

Table 5. Effect of plant extracts on butyrate molar proportion compared with control in in vitro rumen microbial fermentation of a 50:50 forage:concentrate diet

\begin{tabular}{|c|c|c|c|c|c|c|c|}
\hline \multirow[b]{2}{*}{ Treatment } & \multicolumn{5}{|c|}{ Dose (mg/L) } & \multirow[b]{2}{*}{ SEM $^{1}$} & \multirow[b]{2}{*}{$P<$} \\
\hline & 0 & 3 & 30 & 300 & 3,000 & & \\
\hline Anethol & 8.9 & 9.1 & 9.2 & $10.0^{*}$ & $12.5^{*}$ & 0.13 & 0.01 \\
\hline Anise oil & 11.4 & 11.4 & 11.5 & $11.9 *$ & $14.7 *$ & 0.41 & 0.01 \\
\hline Benzyl salicylate & 8.9 & 8.8 & 8.8 & $9.2^{*}$ & $9.2^{*}$ & 0.20 & 0.01 \\
\hline Cade oil & 9.0 & 8.7 & 8.7 & 8.9 & $10.2^{*}$ & 0.53 & 0.01 \\
\hline Capsicum oil & 9.9 & 9.6 & 9.8 & 9.7 & 9.7 & 0.61 & 0.38 \\
\hline Carvacrol & 9.4 & 9.4 & 9.4 & $13.3^{*}$ & $8.5^{*}$ & 0.15 & 0.01 \\
\hline Carvone & 8.9 & 8.9 & 9.0 & $9.5 \dagger$ & $12.6^{*}$ & 0.20 & 0.01 \\
\hline Cinnamaldehyde & 9.4 & 9.3 & 9.3 & 9.8 & 8.8 & 0.19 & 0.04 \\
\hline Cinnamon oil & 10.6 & 10.4 & 10.6 & 10.6 & 10.2 & 1.50 & 0.43 \\
\hline Clove bud oil & 8.9 & 8.9 & 9.0 & $10.3^{*}$ & 9.5 & 0.19 & 0.01 \\
\hline Dillweed oil & 9.0 & 8.6 & 8.7 & 9.0 & $12.2^{*}$ & 0.54 & 0.01 \\
\hline Eugenol & 9.4 & 9.5 & 9.4 & $10.5^{*}$ & $8.9 *$ & 0.12 & 0.01 \\
\hline Fenugreek & 9.0 & 8.8 & 8.8 & 9.0 & 9.3 & 0.36 & 0.37 \\
\hline Garlic oil & 11.4 & 11.8 & 11.0 & $13.3 \dagger$ & $15.4^{*}$ & 0.43 & 0.01 \\
\hline Ginger oil & 9.0 & 8.8 & 8.8 & 8.9 & 9.4 & 0.46 & 0.48 \\
\hline Oregano oil & 10.6 & 10.4 & 10.4 & $11.9^{*}$ & 10.5 & 1.43 & 0.01 \\
\hline Tea tree oil & 9.4 & 9.4 & 9.4 & 9.6 & $13.6^{*}$ & 0.13 & 0.01 \\
\hline Yucca & 9.9 & 9.8 & 9.6 & 9.6 & 10.0 & 0.70 & 0.12 \\
\hline
\end{tabular}

${ }^{1} \mathrm{SEM}=$ Standard error of the means.

* Means within a row differ significantly from control $(P<0.05)$.

$\dagger$ Means within a row differ from control $(P<0.08)$. 
Table 6. Effect of plant extracts on branched-chain VFA molar proportion compared with control in in vitro rumen microbial fermentation of a 50:50 forage:concentrate diet

\begin{tabular}{llllllll}
\hline & \multicolumn{7}{c}{ Dose $(\mathrm{mg} / \mathrm{L})$} \\
\cline { 2 - 5 } Treatment & 0 & 3 & 30 & 300 & 3,000 & SEM $^{1}$ & $P<$ \\
\hline Anethol & 1.9 & 2.0 & 2.0 & 2.0 & 2.1 & 0.05 & 0.31 \\
Anise oil & 1.6 & 1.5 & 1.6 & 1.6 & 1.7 & 0.05 & 0.15 \\
Benzyl salicylate & 1.9 & 1.9 & 2.0 & 1.9 & 1.9 & 0.08 & 0.53 \\
Cade oil & 2.3 & 2.0 & 2.0 & 2.0 & 2.3 & 0.40 & 0.29 \\
Capsicum oil & 1.8 & 1.8 & 1.8 & 1.8 & 1.8 & 0.37 & 0.96 \\
Carvacrol & 2.3 & 2.3 & 2.3 & 2.4 & $1.4^{*}$ & 0.18 & 0.01 \\
Carvone & 1.9 & 2.0 & 2.0 & 2.0 & $1.3^{*}$ & 0.11 & 0.01 \\
Cinnamaldehyde & 2.3 & 2.2 & 2.2 & $2.1^{*}$ & $1.4^{*}$ & 0.15 & 0.01 \\
Cinnamon oil & 1.5 & 1.5 & 1.5 & 1.5 & $0.9^{*}$ & 0.13 & 0.01 \\
Clove bud oil & 1.9 & 2.0 & 2.0 & 1.9 & $1.3^{*}$ & 0.06 & 0.01 \\
Dillweed oil & 2.3 & 2.1 & 2.1 & 2.1 & 2.1 & 0.38 & 0.42 \\
Eugenol & 2.3 & 2.3 & 2.3 & $2.0^{*}$ & $1.4^{*}$ & 0.16 & 0.01 \\
Fenugreek & 2.3 & 2.1 & 2.1 & 1.8 & $1.5^{*}$ & 0.36 & 0.05 \\
Garlic oil & 1.6 & 1.6 & 1.6 & 1.7 & 1.7 & 0.06 & 0.29 \\
Ginger oil & 2.3 & 2.1 & 2.2 & 2.3 & 2.3 & 0.42 & 0.49 \\
Oregano oil & 1.5 & 1.5 & 1.5 & 1.6 & $0.9^{*}$ & 0.15 & 0.01 \\
Tea tree oil & 2.3 & 2.3 & 2.4 & 2.3 & $2.5^{*}$ & 0.19 & 0.04 \\
Yucca & 1.8 & 1.7 & 1.7 & 1.7 & 1.6 & 0.38 & 0.12 \\
\hline \multicolumn{1}{l}{ 1. } & & & & &
\end{tabular}

${ }^{1} \mathrm{SEM}=$ Standard error of the means.

*Means within a row differ significantly from control $(P<0.05)$.

ous studies (Sivropoulou et al., 1996). At $300 \mathrm{mg} / \mathrm{L}$, carvacrol increased the proportion of butyrate, and decreased the proportion of propionate and acetate compared with control. Unexpectedly, at $3,000 \mathrm{mg} / \mathrm{L}$, carvacrol increased the proportion of propionate and decreased the proportion of butyrate but did not affect acetate. These results suggest that changes caused by carvacrol on ruminal microbial fermentation may be contradictory depending on the dose used. Carvacrol is a naturally occurring isomer of thymol (Davidson and Naidu, 2000) and both compounds are considered to have similar antimicrobial activity (Helander et al., 1998). Similar to the results in the present trial with carvacrol, Evans and Martin (2000) observed that 400 $\mathrm{mg} / \mathrm{L}$ of thymol decreased the proportion of acetate and propionate compared with control. Furthermore,

Table 7. Effect of plant extracts on ammonia $\mathrm{N}$ concentration ( $\mathrm{mg}$ of N/100 mL) compared with control in in vitro rumen microbial fermentation of a 50:50 forage:concentrate diet

\begin{tabular}{llllllll}
\hline & \multicolumn{7}{c}{ Dose $(\mathrm{mg} / \mathrm{L})$} \\
\cline { 2 - 6 } Treatment & 0 & 3 & 30 & 300 & 3,000 & SEM $^{1}$ & $P<$ \\
\hline Anethol & 29.0 & 30.1 & 29.4 & 31.8 & 29.1 & 1.17 & 0.50 \\
Anise oil & 19.5 & 15.9 & 18.5 & 19.1 & 17.9 & 1.21 & 0.37 \\
Benzyl salicylate & 29.0 & 29.8 & 30.3 & 29.4 & 29.5 & 0.63 & 0.66 \\
Cade oil & 28.8 & 26.7 & 26.2 & 27.4 & 26.4 & 1.00 & 0.26 \\
Capsicum oil & 15.6 & 14.8 & 14.4 & 15.3 & $9.2^{*}$ & 0.31 & 0.01 \\
Carvacrol & 32.2 & 35.0 & 32.4 & 27.9 & $11.6^{*}$ & 1.99 & 0.01 \\
Carvone & 29.0 & 29.1 & 29.2 & 32.4 & $19.7^{*}$ & 1.19 & 0.01 \\
Cinnamaldehyde & 32.2 & 31.3 & 31.5 & $29.2^{*}$ & $12.4^{*}$ & 1.38 & 0.01 \\
Cinnamon oil & 15.6 & 15.3 & 15.6 & 16.8 & $7.8^{*}$ & 1.18 & 0.01 \\
Clove bud oil & 29.0 & 30.1 & 29.2 & 29.0 & $13.4^{*}$ & 0.87 & 0.01 \\
Dillweed oil & 28.8 & 27.0 & 27.6 & 29.5 & 26.1 & 0.91 & 0.18 \\
Eugenol & 32.2 & 31.7 & 31.8 & $28.6 \dagger$ & $16.9^{*}$ & 2.13 & 0.01 \\
Fenugreek & 28.8 & 26.6 & 26.4 & $23.3^{*}$ & $17.3^{*}$ & 1.56 & 0.01 \\
Garlic oil & 19.5 & 17.0 & 17.2 & 19.6 & 19.6 & 1.07 & 0.30 \\
Ginger oil & 28.8 & 27.9 & 27.8 & $31.3^{*}$ & 29.8 & 0.91 & 0.02 \\
Oregano oil & 15.6 & 14.4 & 14.8 & $18.5^{*}$ & $6.8^{*}$ & 0.54 & 0.01 \\
Tea tree oil & 32.2 & 31.6 & 33.9 & 32.5 & 28.8 & 2.07 & 0.08 \\
Yucca & 15.6 & 13.7 & 14.4 & 14.3 & 11.2 & 1.09 & 0.19 \\
\hline
\end{tabular}

${ }^{1} \mathrm{SEM}=$ Standard error of the means.

*Means within a row differ significantly from control $(P<0.05)$.

$\dagger$ Means within a row differ from control $(P<0.08)$. 
Borchers (1965) and Broderick and Balthrop (1979) observed that $1,000 \mathrm{mg} / \mathrm{L}$ of thymol reduced ammonia $\mathrm{N}$ concentration in batch cultures, which seems to agree with the observed reduction in ammonia $\mathrm{N}$ concentration with carvacrol at $3,000 \mathrm{mg} / \mathrm{L}$. The BCVFA are derived from amino acid catabolism in the rumen (Mackie and White, 1990). The observed reduction in ammonia $\mathrm{N}$ and BCVFA in the present trial suggest that at 3,000 $\mathrm{mg} / \mathrm{L}$ carvacrol reduced amino acid deamination, as was indicated by Broderick and Balthrop (1979) with thymol. Inhibition of amino acid deamination has practical implications because it may increase ruminal escape of dietary protein and improve the efficiency of $\mathrm{N}$ use in the rumen (Van Nevel and Demeyer, 1988). Compounds with phenolic structures, such as thymol and carvacrol, are considered to be more effective as antimicrobials in comparison with other nonphenolic secondary plant metabolites due to the presence of a hydroxyl group in the phenolic structure (Helander et al., 1998; Ultee et al., 2002). In general, gram-positive bacteria appear to be more susceptible to inhibition by plant essential oil compounds compared with gram-negative bacteria (Davidson and Naidu, 2000). This effect has been related to the presence of an outer membrane on gram-negative organisms, which endows them with a hydrophilic bacterial surface that acts as a strong impermeability barrier (Nikaido, 1994). However, Helander et al. (1998) reported that thymol and carvacrol also inhibit growth of gram-negative bacteria by disrupting the outer cell membrane. They attributed this inhibitory activity to the presence of a phenolic group. Ultee et al. (2002) suggested that carvacrol acted as a transmembrane carrier of monovalent cations by exchanging its hydroxyl proton (from the phenolic group) for a cation such as potassium. These events would result in the absence of a proton motive force, a reduction in the synthesis of ATP, and finally to cell death. All the observed effects suggest that carvacrol has a low antimicrobial specificity and may inhibit gram-positive (most acetate- and butyrate-producing bacteria) or gram-negative bacteria (normally propionate-producing bacteria) in a dose-dependent manner, which suggests that its use may not be adequate in a complex microbial environment such as the rumen.

Similarly to carvacrol, eugenol is also a phenolic compound and its mode of action as an antimicrobial is also thought to be related to the presence of a hydroxyl group (Davidson and Naidu, 2000). However, in the present trial, its effects on $\mathrm{pH}$, total and individual VFA proportions, and ammonia $\mathrm{N}$ concentration were also similar to those observed with the nonphenolic compound cinnamaldehyde. Other authors have observed similar antimicrobial effects in both substances
(Wendakoon and Sakaguchi, 1995; Davidson and Naidu, 2000), which may be attributed to both compounds belonging to the phenylpropanoid group and having similar chemical structures. Eugenol has been shown to be the major antimicrobial compound in clove bud oil (containing $85 \%$ of eugenol; Davidson and Naidu, 2000), whereas cinnamaldehyde is the main compound of cinnamon oil (containing 59\% of cinnamaldehyde; Davidson and Naidu, 2000). In the present trial, eugenol and clove bud oil increased the $\mathrm{pH}$ and decreased total VFA and ammonia N concentrations. However, the propionate molar proportion was only increased by eugenol, and the acetate molar proportion only decreased by clove bud oil. The concentration of BCVFA increased in both substances at $300 \mathrm{mg} / \mathrm{L} \mathrm{com-}$ pared with control, but it decreased in eugenol when the dose was increased to $3,000 \mathrm{mg} / \mathrm{L}$. The different effects of eugenol and clove bud oil suggest that other compounds in clove bud oil may interact with eugenol and exert additional effects. In fact, in a previous in vitro study in a continuous culture system (Busquet et al., 2005b), low doses of clove bud oil (2.2 mg/L) resulted in lower molar proportions of acetate and BCVFA and a higher molar proportion of propionate, whereas the same dose of eugenol did not show any effects.

Cinnamon oil and its main active component cinnamaldehyde resulted in different effects. High doses of cinnamon oil and cinnamaldehyde decrease the total VFA, BCVFA, and ammonia $\mathrm{N}$ concentrations, although cinnamaldehyde had stronger inhibitory effects. However, the $\mathrm{pH}$ and the proportion of propionate were only increased by cinnamaldehyde, and the acetate proportion was only increased by cinnamon oil. These results suggest that, although cinnamaldehyde is the main and most active component in cinnamon oil, other substances within cinnamon oil may interact with cinnamaldehyde. In a previous in vitro study in a continuous culture system (Busquet et al., $2005 b)$, a low concentration of cinnamaldehyde (2.2 $\mathrm{mg} / \mathrm{L})$ numerically $(P=0.11)$ decreased the proportion of acetate and numerically $(P=0.11)$ increased the proportion of butyrate, but had no effect on propionate. The variability of these results compared with those of the present trial could be due to the different doses used, a different in vitro system (batch vs. continuous culture), or the length of incubation period ( $24 \mathrm{~h}$ in batch fermentation and $9 \mathrm{~d}$ in continuous culture), which may have allowed for the adaptation of rumen microflora to the effects of essential oils. Several studies have shown the antimicrobial effects of cinnamaldehyde over several targeted microorganisms (Helander et al., 1998; Smith-Palmer et al., 1998; Kim et al., 2004). Similarly to other secondary plant metabo- 
lites, gram-positive bacteria are more sensitive to the inhibition by cinnamaldehyde (Smith-Palmer et al., 1998), although some studies have demonstrated that purified cinnamaldehyde was also highly effective on gram-negative bacteria (Helander et al., 1998; Kim et al., 2004). Helander et al. (1998) observed that, in contrast with other secondary plant metabolites (thymol and carvacrol), cinnamaldehyde had no outer membrane disintegrating activity nor depletion of intracellular ATP, suggesting that cinnamaldehyde could gain access to the periplasm and to the deeper parts of the cell probably through the outer membrane traversing porin proteins (Nikaido, 1994). Although the mechanism of action of cinnamaldehyde as an antimicrobial remains poorly understood, some authors suggested that the carbonyl group might be the active site (Wendakoon and Sakaguchi, 1995; Helander et al., 1998).

The anise oil and its main component anethol had similar effects on rumen microbial fermentation profile. Both compounds decreased total VFA and the proportion of acetate and propionate, and increased the proportion of butyrate, although anethol had stronger effects compared with anise oil. In contrast with other essential oils, anise oil and anethol did not affect ammonia $\mathrm{N}$ concentration. Numerous studies have demonstrated that anethol is the main antimicrobial active molecule of anise oil (Davidson and Naidu, 2000), which agrees with the results observed in the present trial. In general, the antimicrobial activity of anethol has been related to the ether group on its aromatic ring (Davidson and Naidu, 2000). Although anethol had a high capacity to modify rumen microbial fermentation, it reduced the proportion of acetate and propionate, which are the main precursors in ruminants for fat and glucose synthesis, respectively, which suggests that anethol may not be nutritionally beneficial to dairy cattle.

Carvone, dill oil, and tea tree oil had similar effects to those observed in anethol and anise oil, although at $3,000 \mathrm{mg} / \mathrm{L}$, carvone and tea tree oil also decreased the ammonia $\mathrm{N}$ concentration. Carvone is present in dill oil (containing $47 \%$ of carvone) and is thought to be responsible for its antimicrobial activity (Davidson and Naidu, 2000), which agrees with the results observed in the present trial. Dorman and Deans (2000) observed that carvone was active against gram-positive and gram-negative bacteria, due to its high solubility (low saturation) in water, and the presence of a ketonic group and one double bond on the molecule. Tea tree oil has a membrane-active biocide capacity with broad-spectrum activity (Davidson and Naidu, 2000). Terpinen-4-ol is considered the main active component (up to about $40 \%$ ) of tea tree oil, whereas nonoxygenated terpenoid hydrocarbons (like terpinene and cymene) account for the rest (approximately $50 \%$ ) of the compounds in this oil (Cox et al., 2001). Cox et al. (2001) observed that different terpenoid components of tea tree oil could interact in an aqueous dispersion to either reduce or increase its antimicrobial efficacy, depending upon their relative concentrations and the overall susceptibility of the target microorganism. In general, the nonoxygenated monoterpene hydrocarbons appear to produce antagonistic effects with terpinen-4-ol against more tolerant microorganisms. This effect is probably related to the fact that the nonaqueous monoterpene (nonoxygenated hydrocarbons) phase reduces aqueous terpinen-4-ol solubility and, therefore, its microbial availability. Such effects may have significant implications in formulations containing tea tree oil as the main antimicrobial.

High doses of garlic oil resulted in a reduction in total VFA and the proportion of acetate, and an increase in the proportions of propionate and butyrate. The effects observed in garlic oil in the present trial are consistent with previous reports (Busquet et al., 2005a) and are similar to those normally found with methane inhibitors such as amicloral (Chalupa et al., 1980) or 2-bromoethanosulfonic acid (Martin and Macy, 1985), which directly inhibit methanogenic Archaea or the metabolic pathways of methane synthesis. The direct inhibition of methane production by these additives leads to an excess of hydrogen in the rumen, that needs to be diverted to other hydrogen sinks such as propionate and butyrate (Demeyer and Van Nevel, 1975), and in a high $\mathrm{NADH} \mathrm{NAD}^{+}$ratio that results in a decrease in acetate production (Miller, 1995). The antimicrobial activity of garlic oil has been attributed to the presence of organosulfur compounds, and particularly to allicin (Reuter et al., 1996; Ankri and Mirelman, 1999). Some authors suggested that $\mathrm{SH}$-groups of the organosulfur compounds found in garlic oil are the main active site, and modify microbial metabolism through their interaction with other $\mathrm{SH}$ groups of microbial proteins and other biological active molecules by a thiol-disulfide exchange reaction (Reuter et al., 1996). We hypothesize that the effects observed with garlic oil in the present trial could be related to the capacity of its organosulfur compounds to specifically inhibit SH-containing enzymes participating in different activities of the Archaea (methanogenic microorganisms domain) metabolism. In fact, numerous studies have demonstrated the inhibitory effects of garlic-derived organosulfur compounds on the enzyme 3-hydroxy-3-methyl-glutaryl coenzyme A (HMG-CoA) reductase (catalyze the synthesis of cholesterol in humans and that of the isoprenoid units in the membrane lipids in methanogenic archaea) activ- 
ity (Gebhardt and Beck, 1996; Cho and Xu, 2000). Miller and Wolin (2001) demonstrated that products, such lovastatin and mevastatin, which decrease cholesterol production in humans by inhibiting 3-hydroxy3-methyl-glutaryl-CoA reductase, have the potential to specifically inhibit rumen methanogenic Archaea without affecting rumen bacteria (Eubacteria) due to their different membrane lipid composition.

Benzyl salicylate had similar effects to those observed with garlic oil (increase in the proportion of propionate and butyrate and decrease in the proportion of acetate) although to a lesser extent. These results suggest that this compound could also inhibit methane production in the rumen by direct inhibition of methanogenic Archaea or the metabolic pathways of methane synthesis. However, the lack of literature on the antimicrobial effects of this compound makes it difficult to hypothesize on its mechanism of action on rumen microbial fermentation.

In contrast with most essentials oil and their secondary constituents, fenugreek extract did not reduce the concentration of total VFA even at high doses, which suggests that it did not reduce diet fermentability and energy availability. Fenugreek decreased the proportion of BCVFA, increased the proportion of propionate, and reduced the ammonia $\mathrm{N}$ concentration. These effects can be attributed to the high content in steroidal saponins. However, yucca extract, which also contains saponins, had no effect on rumen microbial fermentation. It is likely that the lack of effect of yucca extract on rumen microbial fermentation is related to the high $\mathrm{pH}$ used in the test. Cardozo et al. (2005) recently demonstrated that the effect of yucca saponins on rumen microbial fermentation was highly dependent on the $\mathrm{pH}$ of the media. In addition, fenugreek has more than twice the amount of saponins compared with yucca extract. Several studies have evaluated the effects of saponins on rumen fermentation. A consistent finding when saponins are supplied to ruminants is a reduction in ruminal ammonia $\mathrm{N}$ concentration (Wallace et al., 1994; Hristov et al., 1999). These effects have been generally attributed to the pronounced antiprotozoal activity of saponins (Francis et al., 2002), protozoa being the primary rumen ammonia producers. The antiprotozoal effects of saponins is due to their capacity to form irreversible complexes with the cholesterol in the protozoal cell membrane, causing breakdown of the membrane, cell lysis, and death (Francis et al., 2002). Contrary to the increase of $\mathrm{pH}$ observed in essential oils and its main active components, fenugreek and yucca extracts decreased $\mathrm{pH}$ compared with control. Decreased ruminal $\mathrm{pH}$ associated with saponins supplementation has been reported previously (Wu et al., 1994; Lila et al., 2003). Klita et al. (1996) suggested that reduction of protozoa is also mediated through the $\mathrm{pH}$ reduction by saponins, which could have resulted in a further reduction of protozoa numbers in the present trial. Although the most obvious effect of saponins on ruminal microbes is the suppression of protozoa, Wallace et al. (1994) also observed inhibitory effects on ruminal bacteria. The antibacterial properties of saponins seem to be more pronounced against gram-positive bacteria (similar to the action of ionophores), and involve membranolytic properties (Killeen et al., 1998). Some studies reported an increase in propionate and a decrease in acetate concentrations when saponins were added (Hristov et al., 1999; Lila et al., 2003), which agrees with the results observed in the present trial, although others have not observed any effects (Klita et al., 1996), which suggests that these effects may vary with diet and the dose used. The increase in the proportion of propionate in the rumen has been associated with a decrease in gram-positive bacteria, which are normally acetate-, but not propionate-, producers (Wallace et al., 1994). It is possible that the inhibitory effect of saponins on bacteria and protozoa not involved in propionate production allowed gram-negative, propionate-producer species such as Selenomonas ruminantium to fill the niche, thereby increasing the accumulation of propionate in the rumen.

Cade oil, capsicum oil, and ginger oil resulted in small or nonsignificant effects on rumen microbial fermentation compared with control. Although several studies demonstrated the antimicrobial activity of these compounds (Davidson and Naidu, 2000), results suggests that, in the conditions used in the present trial, they were not effective as rumen microbial modulators. The lack of effects of cade oil, capsicum oil, and ginger oil compared with other plant essential oils could be related to its low content of oxygenated hydrocarbons, as some studies observed that, in general, hydrocarbon monoterpenes are significantly less active than are oxygenated monoterpenes (Dorman and Deans, 2000; Cox et al., 2001).

The results observed in the present trial suggest that careful selection of plant extracts may help to improve efficiency of rumen microbial fermentation. However, previous long-term in vitro studies with plant extracts (Wang et al., 1998; Cardozo et al., 2004; Busquet et al., 2005b) demonstrated that the effects of some plant extracts on rumen microbial fermentation disappeared after several days of incubation, suggesting that ruminal microorganisms may adapt to the presence of these compounds. Future research in long-term studies may help to establish the efficacy of these plant extracts as rumen microbial modulators. 


\section{CONCLUSIONS}

High doses of plant extracts and secondary plant metabolites resulted in detrimental effects on rumen microbial fermentation (decrease in total VFA concentration), except in cade oil, capsicum oil, dill oil, ginger oil, and extracts rich in saponins (fenugreek and yucca). Anethol, anise oil, carvone, and tea tree oil decreased the proportion of acetate and propionate, and increased the proportion of butyrate. Garlic oil and benzyl salicylate reduced the acetate and increased the propionate and butyrate proportions, which suggests an antimethanogenic effect. Cade oil, capsicum oil, and ginger oil resulted in small effects on rumen microbial fermentation probably related to their low content in oxygenated hydrocarbons. High doses of fenugreek $(300$ and $3,000 \mathrm{mg} / \mathrm{L}$ ) resulted in reductions in ammonia $\mathrm{N}$ concentrations of 19.2 and $39.1 \%$, respectively. Careful selection and combination of these additives may allow the manipulation of rumen microbial fermentation. However, their efficacy requires determination of potential ruminal adaptation in long-term in vivo feeding conditions.

\section{ACKNOWLEDGMENTS}

The authors would like to thank the support and technical assistance provided by Pancosma S. A.

\section{REFERENCES}

Ankri, S., and D. Mirelman. 1999. Antimicrobial properties of allicin from garlic. Microbes Infect. 2:125-129.

Borchers, R. 1965. Proteolytic activity of rumen fluid in vitro. J. Anim. Sci. 24:1033-1038.

Broderick, G. A., and J. E. Balthrop. 1979. Chemical inhibition of amino acid deamination by ruminal microbes in vitro. J. Anim. Sci. 49:1101-1111.

Busquet, M., S. Calsamiglia, A. Ferret, and C. Kamel. 2005a. Effects of cinnamaldehyde and garlic oil on rumen microbial fermentation in a dual flow continuous culture. J. Dairy Sci. 88:25082516.

Busquet, M., S. Calsamiglia, A. Ferret, and C. Kamel. 2005b. Screening for effects of plant extracts and secondary plant metabolites on rumen microbial fermentation. Anim. Feed Sci. Technol. 123/ 124:597-613.

Cardozo, P. W., S. Calsamiglia, A. Ferret, and C. Kamel. 2004. Effects of natural plant extracts on ruminal protein degradation and fermentation profiles in continuous culture. J. Anim. Sci. 82:3230-3236.

Cardozo, P. W., S. Calsamiglia, A. Ferret, and C. Kamel. 2005. Screening for the effects of natural plant extracts at two $\mathrm{pH}$ levels on in vitro rumen microbial fermentation of a high-concentrate diet for beef cattle. J. Anim. Sci. 88:2572-2579.

Chalupa, W., W. Corbett, and J. R. Brethour. 1980. Effects of monensin and amicloral on rumen fermentation. J. Anim. Sci. $51: 170-179$

Chaney, A. L., and E. P. Marbach. 1962. Modified reagents for determination of urea and ammonia. Clin. Chem. 8:130-132.

Cho, S. B. H., and S. Xu. 2000. Effects of allyl mercaptan and various allium-derived compounds on cholesterol synthesis and secretion in Hep-G2 cells. Comp. Biochem. Physiol. C, Comp. Pharmacol. Toxicol. 126:195-201.
Cox, S. D., C. M. Mann, and J. L. Markam. 2001. Interaction between components of the essential oil of Melaleuca alternifolia. J. Appl. Microbiol. 91:492-497.

Davidson, P. M., and A. S. Naidu. 2000. Phyto-phenols. Pages 265293 in Natural Food Antimicrobial Systems. A. S. Naidu, ed. CRC Press, Boca Raton, FL.

Demeyer, D. I., and C. J. Van Nevel. 1975. Methanogenesis, an integrated part of carbohydrate fermentation, and its control. Pages 366-382 in Digestion and Metabolism in the Ruminant. I. W. McDonald and A. C. I. Warner, ed. Univ. New England Publ. Unit, Armidale, Australia.

Dorman, J. J. D., and S. G. Deans. 2000. Antimicrobial agents from plants: Antibacterial activity of plant volatile oils. J. Appl. Microbiol. 88:308-316.

Evans, J. D., and S. A. Martin. 2000. Effects of thymol on ruminal microorganisms. Curr. Microbiol. 41:336-340.

FDA. 2004. Food and Drug Administration of the US, 21 CFR 184. http://www.cfsan.fda.gov/ lrd/FCF184.html Accessed Sep. 20, 2004

Francis, G., Z. Kerem, H. P. S. Makkar, and K. Becker. 2002. The biological action of saponins in animal systems: Reviews. Br. J. Nutr. 88:587-605.

Gebhardt, R., and H. Beck. 1996. Differential inhibitory effects of garlic-derived organosulfur compounds on cholesterol biosynthesis in primary rat hepatocyte cultures. Lipids 31:1269-1276.

Helander, I. M., H. Alakomi, K. Latva-Kala, T. Mattila-Sandholm, I. Pol, E. J. Smid, L. G. M. Gorris, and A. Wright. 1998. Characterisation of the action of selected essential oil components on gram-negative bacteria. J. Agric. Food Chem. 46:3590-3595.

Hristov, A. N., T. A. McAllister, F. H. Van Herk, K. J. Cheng, C. J. Newbold, and P. R. Cheeke. 1999. Effect of Yucca schidigera on ruminal fermentation and nutrient digestion in heifers. J. Anim. Sci. 77:2554-2563.

Jouany, J. P. 1982. Volatile fatty acids and alcohol determination in digestive contents, silage juice, bacterial cultures and anaerobic fermentor contents. Sci. Aliments 2:131-144.

Killeen, G. F., C. A. Madigan, C. R. Connolly, G. A. Walsh, C. Clark, M. J. Hynes, B. F. Timmins, P. James, D. R. Headon, and R. F. Power. 1998. Antimicrobial saponins of Yucca schidigera and the implications of their in vitro properties for their in vivo impact. J. Agric. Food Chem. 46:3178-3186.

Kim, H. O., S. W. Park, and H. D. Park. 2004. Inactivation of Escherichia coli $\mathrm{O} 157: \mathrm{H} 7$ by cinnamic aldehyde purified from Cinnamomum cassia shoot. Food Microbiol. 21:105-110.

Klita, P. T., G. W. Mathison, T. W. Fenton, and R. T. Hardin. 1996. Effects of alfalfa root saponins on digestive function in sheep. J. Anim. Sci. 74:1144-1156.

Lila, Z. A., N. Mohammed, S. Kanda, T. Kamada, and H. Itabashi. 2003. Effect of sarsaponin on ruminal fermentation with particular reference to methane production in vitro. J. Dairy Sci. 86:3330-3336.

Mackie, R. I., and B. A. White. 1990. Recent advances in rumen microbial ecology and metabolism: Potential impact on nutrient output. J. Dairy Sci. 73:2971-2995.

Martin, S. A., and J. M. Macy. 1985. Effects of monensin, pyromellitic diimide and 2-bromoethanosulfonic acid on rumen fermentation in vitro. J. Anim. Sci. 60:544-550.

McDougall, E. I. 1948. Studies on ruminant saliva. 1: The composition and output of sheep's saliva. Biochem. J. 43:99-109.

McGuffey, R. K., L. F. Richardson, and J. I. D. Wilkinson. 2001. Ionophore for dairy cattle: Current status and future outlook. J. Dairy Sci. 84(E. Suppl.):E194-E203.

Miller, T. L. 1995. Ecology of methane production and hydrogen sinks in the rumen. Pages 317-331 in Ruminant Physiology. W. Engelhardt, S. Leonhard-Marek, G. Breves, and D. Giesecke, ed. Stuttgart, Germany.

Miller, T. L., and M. J. Wolin. 2001. Inhibition of growth of methaneproducing bacteria of the ruminant forestomach by hydroxymethylglutaryl-ScoA reductase inhibitors. J. Dairy Sci. $84: 1445-1448$.

Nikaido, H. 1994. Prevention of drug access to bacterial targets: Permeability barriers and active efflux. Science 264:382-388. 
NRC. 2001. Nutrient Requirements of Dairy Cattle. 7th rev. ed. Natl. Acad. Press, Washington, DC.

Oh, H. K., T. Sakai, M. B. Jones, and W. M. Longhurst. 1967. Effect of various essential oils isolated from Douglas fir needles upon sheep and deer rumen microbial activity. Appl. Microbiol. 15:777-784.

Reuter, H. D., J. P. Koch, and L. Lawson. 1996. Therapeutic effects and applications of garlic and its preparations. Pages 135-212 in Garlic. The Science and Therapeutic Application of Allium sativum L. and Related Species. H. P. Koch and L. D. Lawson, ed. Williams \& Wilkins, Baltimore, MD.

Russell, J. B., and A. J. Houlihan. 2003. Ionophore resistance of ruminal bacteria and its potential impact on human health. FEMS Microbiol. Rev. 27:65-74.

Sivropoulou, A., E. Papanikolau, C. Nikolau, S. Kokkini, T. Lanaras, and M. Arsenakis. 1996. Antimicrobial and cytotoxic activities of Origanum essential oils. J. Agric. Food Chem. 44:1202-1205.

Smith-Palmer, A., J. Stewart, and L. Fyfe. 1998. Antimicrobial properties of plant essential oils and essences against five important food-borne pathogens. Lett. Appl. Microbiol. 26:118-122.

Tamminga, S. 1992. Nutrition management of dairy cows as a contribution to pollution control. J. Dairy Sci. 75:345-357.
Ultee, A., M. H. J. Bennik, and R. Moezelaar. 2002. The phenolic hydroxyl group of carvacrol is essential for action against the food-borne pathogen Bacillus cereus. Appl. Environ. Microbiol. 68:1561-1568.

Van Nevel, C. J., and D. I. Demeyer. 1988. Manipulation of rumen fermentation. Pages 387-443 in The Rumen Microbial Ecosystem. P. N. Hobson, ed. Elsevier Applied Science, London, UK.

Van Soest, P. J. 1982. Nutritional Ecology of the Ruminant. Comstock, Cornell Univ. Press, New York, NY.

Wallace, R. J., L. Arthaud, and C. J. Newbold. 1994. Influence of Yucca shidigera extract on ruminal ammonia concentrations and ruminal microorganisms. Appl. Environ. Microbiol. 60:1762-1767.

Wang, Y., T. A. McAllister, C. J. Newbold, L. M. Rode, P. R. Cheeke, and K. J. Cheng. 1998. Effects of Yucca schidigera extract on fermentation and degradation of steroidal saponins in the rumen simulation technique (Rusitec). Anim. Feed Sci. Technol. 74:143-153

Wendakoon, C. N., and M. Sakaguchi. 1995. Inhibition of amino acid decarboxylase activity of Enterobacter aerogenes by active components in spices. J. Food Prot. 58:280-283.

Wu, Z., M. Sadik, F. T. Sleiman, J. M. Simas, M. Pessarakli, and J. T. Huber. 1994. Influence of yucca extract on ruminal metabolism in cows. J. Anim. Sci. 72:1038-1042. 